\title{
Meteorological source variability in atmospheric gravity wave parameters derived from a tropical infrasound station
}

Article

Accepted Version

Marlton, G. J., Charlton-Perez, A. J., Harrison, R. G., Blanc, E., Evers, L., Le-Pichon, A. and Smets, P. S. M. (2019) Meteorological source variability in atmospheric gravity wave parameters derived from a tropical infrasound station. Journal of Geophysical Research: Atmospheres, 124 (8). pp. 43524364. ISSN 2169-897X doi:

https://doi.org/10.1029/2018JD029372 Available at https://centaur.reading.ac.uk/82971/

It is advisable to refer to the publisher's version if you intend to cite from the work. See Guidance on citing.

To link to this article DOI: http://dx.doi.org/10.1029/2018JD029372

Publisher: American Geophysical Union

All outputs in CentAUR are protected by Intellectual Property Rights law, including copyright law. Copyright and IPR is retained by the creators or other copyright holders. Terms and conditions for use of this material are defined in the End User Agreement. 


\section{CentAUR}

Central Archive at the University of Reading

Reading's research outputs online 
Marlton Graeme (Orcid ID: 0000-0002-8466-6779)

Charlton-Perez Andrew, James (Orcid ID: 0000-0001-8179-6220)

Harrison R. Giles (Orcid ID: 0000-0003-0693-347X)

Evers Laslo, Gerardus (Orcid ID: 0000-0003-2825-6211)

Le Pichon Alexis (Orcid ID: 0000-0001-6531-069X)

Smets Pieter, Steven Maarten (Orcid ID: 0000-0003-0394-0973)

\section{Meteorological source variability in atmospheric gravity wave parameters derived from a tropical infrasound station}

G.J. Marlton ${ }^{1}$, A.J. Charlton-Perez ${ }^{1}$, R.G. Harrison ${ }^{1}$, E. Blanc ${ }^{2}$, L. Evers ${ }^{3,4}$, A. LePichon $^{2}$ and P.S.M. Smets ${ }^{3,4}$

${ }^{1 \dagger}$ Department of Meteorology, University of Reading, Reading, United Kingdom, RG6 6BB, UK

${ }^{2}$ CEA - CEA, DAM, DIF, F-91297, France.

${ }^{3}$ KNMI - Royal Netherlands Meteorological Institute, R\&D Seismology and Acoustics;

${ }^{4}$ TU Delft, Geoscience and Engineering, Netherlands

Corresponding author: Graeme Marlton (graeme.marlton@ reading.ac.uk)

$†$ Current Address.

\section{Key Points:}

-Variations in gravity wave activity at a tropical infrasound station are linked with daily and seasonal local and remote convective cycles.

-Gravity wave travel distance effects the wavelength, speed and amplitude of gravity waves

- Gravity waves took on average 6 hours to propagate from a thunderstorm source to microbarometer array.

This article has been accepted for publication and undergone full peer review but has not been through the copyediting, typesetting, pagination and proofreading process which may lead to differences between this version and the Version of Record. Please cite this article as doi: 10.1029/2018JD029372

(c) 2019 American Geophysical Union. All rights reserved. 


\begin{abstract}
Gravity waves are an important part of the momentum budget of the atmosphere. Despite this, parameterizations of gravity wave spectra in atmospheric models are poorly constrained. Gravity waves are formed by jet streams, flow over topography and convection, all of which produce pressure perturbations as they propagate over the Earth's surface, detectable by microbarometer arrays used for sensing infrasound. In this study, observations of gravity waves between 2007 and 2011 at an infrasound station in the Ivory Coast, West Africa are combined with meteorological data to calculate parameters such as intrinsic phase speed and wavenumber. Through spectral analysis, the seasonal and daily variations in all gravity wave parameters are examined. The gravity wave back azimuth varies with the migration of the Inter-Tropical Convergence Zone, a region of intense convection, supporting previous studies. Daily variations in gravity wave arrivals at the station can be linked to two distinct convective cycles over the land and ocean. This was achieved by combining the gravity wave parameters with lightning strikes detected by the Met Office's Arrival Time Difference lightning detection system. Noise generated by turbulence in the middle of the day was found to attenuate smaller pressure amplitude gravity waves, artificially amplifying the daily variations in some gravity wave parameters. Detection of daily and seasonal variations in gravity wave parameters has the potential be used to improve the representation of gravitywave spectra in atmospheric models.
\end{abstract}

\title{
1 Introduction
}

Convection, topography and jet streams cause atmospheric disturbances which lead to the generation of atmospheric gravity waves (Fritts and Alexander, 2003). Gravity waves are important as they transport momentum through the atmosphere, which affects the stratospheric circulation (Beres et al 2004), and they generate turbulence as they break (Knox et al, 2008). Despite their importance, parameterizations for gravity waves are ill-constrained in models and more observations are needed to improve them (Beres et al 2004, Richter et al 2010 and Lott \& Guez 2013). In their review, Geller et al (2013) demonstrate that there are few observation methods for gravity wave detection that have extensive temporal and global coverage. Most existing observations originate from satellite measurements which observe gravity waves in the stratosphere (de Groot-Hedlin, et al 2017). At the surface, gravity waves produce perturbations in surface pressure which can be observed using sensitive barometers. Time series of microbarometer data have been used previously to infer gravity wave properties at the surface (Balachandran 1980, Aplin \& Harrison 2003, Le-Pichon et al 2002, and Marlton et al 2018).

The direction and velocity of wave propagation can be derived using arrays of three or more instruments (Le-Pichon et al, 2002, Farges et al 2003, Blanc et al 2014). Larger arrays of barometers such as those used in the USArray network, have been used to detect convectively generated gravity waves at the surface with time periods of 2-6 hours (Balachandran 1980, Jacques et al 2015, de Groot-Hedlin et al 2017). However, the microbarometer network used in de Groot-Hedlin et al (2017) only covers parts of the mainland U.S. In contrast, the Comprehensive Nuclear-Test-Ban-Treaty Organization's (CTBTO) International Monitoring System (IMS) will consist of 60 microbarometer arrays, also referred to as Infrasound Stations (IS), across the globe (Christie et al 2010) used as a verification technique for atmospheric nuclear tests (Dahlman et al. 2009). Currently, 49 arrays have been installed and certified, providing data in real time to the International Data Center (IDC) in Vienna (status 
in June 2018). Infrasound microbarometers measure small pressure fluctuations on the order of $\mathrm{mPa}$ up to tens of pascals with a flat response over the frequency band from 0.08 to $4 \mathrm{~Hz}$ sampled at $20 \mathrm{~Hz}$ (Ponceau and Bosca, 2010). Gravity waves have frequencies much lower than $0.08 \mathrm{~Hz}$ and generate pressure perturbations several orders larger than that of infrasound. This, combined with the flat response range results in a reduction in pressure amplitude at lower frequencies. A transfer function is therefore applied to the infrasound data to correct for the response as a function of frequency. Each infrasound array consists of at least four microbarometers with an array aperture of approximately $1 \mathrm{~km}$, which provides a global network, capable of detecting and characterizing gravity waves as demonstrated in Marty et al (2010). Some IMS stations have been operational for over a decade allowing local gravity wave climatologies to be created. Blanc et al (2014) undertook an analysis of 10 years of GW observations from Infrasound station 17 (IS17), located in the Ivory Coast, Western Africa, and found seasonal variations in the gravity wave back azimuth due to a seasonal shift in the Inter Tropical Convergence Zone (ITCZ), as inferred by a satellite borne Lightning Imaging Sensor (LIS). The ITCZ is a zone of low pressure that forms at the convergence of the north and south trade winds, causing convection. It shifts northwards in Northern Hemisphere (NH) summer and Southwards in NH winter, due to radiative heating (Wallace and Hobbs 2006). Convective systems in this region form from approximately $1 \mathrm{~km}$ and can extend up approximately $12 \mathrm{~km}$ (Stein et al 2015)

In this study, the analysis in Blanc et al (2014) is extended by combining the GW measurements with meteorological observations to calculate wavenumbers and velocity perturbations as shown in Marlton et al (2018) and summarized in section 2. The aim of this is to allow the easier use of $\mathrm{GW}$ data from infrasound networks for meteorological applications. In the remainder of this study lightning strike location data from the Met Office's ATDnet lightning system to link the observed GW timeseries at IS17 to daily and seasonal variations in local thunderstorm activity.

\section{Deriving gravity wave parameters from the Ivory Coast infrasound station}

Infrasound Station 17 (IS17) is a four-element infrasound array located in the Ivory Coast, West Africa, $6.67 \mathrm{~N}, 4.89 \mathrm{~W}$, approximately $180 \mathrm{~km}$ inland from the east Atlantic Ocean. The four microbarometers are arranged in a triangular configuration with the fourth instrument at the center, with a distance between each microbarometer of approximately $1 \mathrm{~km}$. As a gravity wave passes over the array it induces pressure perturbations, delayed sequentially at each microbarometer. A gravity wave's back azimuth $\phi$, pressure perturbation $p$ ' and ground based phase velocity $c$, and frequency $\omega$ can be derived from differences between the individual sensor time series. Two methods can be implemented to achieve this. Firstly, a Progressive Multi-Channel Correlation (PMCC) algorithm originally described in Cansi (1995) and adapted by Le-Pichon et al (2002) and Farges (2003) is suitable for use on infrasonic and gravity waves. Secondly a Fisher statistical test can be used to see if the multiple time-shifted pressure time series are correlated (Evers 2008) in the time domain (Melton and Bailey 1957) or frequency domain (Smart and Flinn 1971). For this analysis, gravity waves detected at IS17 using the PMCC method are used with the following assumption, the waves are linear plane waves with no curvature as they are distant from their source. The PMCC analysis implemented here scanned the pressure time series for gravity waves with periodicities from 10 minutes to 165 minutes.

Lindzen and Tung (1976), Balachandran (1980) Chimonas and Hines (1986) showed that gravity waves detected near the surface and for long periods are likely to be ducted waves. Figure 1 shows averaged profiles of the $\mathrm{u}$ and $\mathrm{v}$ wind components and Brunt-Vaisala 
frequency N, squared over IS17 form the European Centre for Medium range Weather Forecasting (ECMWF) high resolution model. A low-level jet peaks at $4 \mathrm{~km}$ and $\mathrm{N}$ makes a step change at this height indicating the presence of temperature and wind ducting mechanisms up to a height of approximately $4 \mathrm{~km}$ (Chimona and Hines 1986, Crook 1988, and Nappo 2013). Furthermore, the gravity waves detected in Blanc et al (2014) are detected $100 \mathrm{~km}$ away from the convective source, indicating a ducting mechanism is present stopping the gravity waves propagating away into the upper atmosphere.

A ducted gravity wave has differing relationships in term of the dispersion equations, which govern the relationship between their horizontal wave numbers, $k_{H}$ and vertical wave numbers $m$. However, the basic equations to calculate the wave quantities: intrinsic frequency $\widehat{\omega}$, intrinsic phase velocity $\hat{c}$ and $k_{H}$ are the same as that for a classical wave. We undertake our analysis using the intrinsic quantities to remove the effects of the wind near the surface, it should be noted that the wind profile changes with height as shown in figure 1 , and that the parameters calculated here are only valid near the surface. $\hat{c}$ is obtained using

$$
\hat{c}=c-U_{P},
$$

where $U_{p}$ is the wind speed along the propagation direction of the gravity wave and is found from weather station data sited at the array. Hence, $\widehat{\omega}$ can be calculated using

$$
\widehat{\omega}=\omega-\frac{U_{p}}{\lambda},
$$

where $\lambda$ is the horizontal wave length of the gravity wave. However, $\lambda$ is unknown so we can substitute $\lambda=c / \omega$ into (2) and rearrange to give

$$
\widehat{\omega}=\left(1-\frac{U_{p}}{c}\right) \omega
$$

$k_{H}$ can be found by using $k_{H}=\omega / c$. Using the polarization equations (Gill 1982) where the horizontal velocity perturbation $u$ ' is given by

$$
u^{\prime}=\frac{p \prime}{\rho \hat{c}}
$$

where $\rho$ is the density of air, which is a function of temperature, pressure and humidity, for which surface values were obtained from the array's meteorological station. For the calculations undertaken here, humidity is included in the density calculation: without this, Marlton et al (2018) show that the density of air at warm humid locations could be up to $2 \%$ less than that given using a dry air approximation. The array's meteorological station is mounted at $2 \mathrm{~m}$ above the surface and it is this height for which the values of $u$ ' are valid. It has been shown by Gossard and Munk (1954) that pressure and wind perturbations near the surface are correlated, allowing the use of (4). $m$ can be calculated using the following approximation (Nappo 2013)

$$
m^{2} \sim k_{H}^{2}\left(\frac{N^{2}}{\widehat{\omega}^{2}}-1\right)
$$

where, $N$ is the Brunt-Vaisala frequency which is of the order of $0.01 \mathrm{~s}^{-1}$ in the free troposphere. However, there are implications for using this approximation for ducted waves as the vertical wavelengths it may approximate may be larger than the wave duct, which can be permitted under certain conditions and assumptions discussed in Lindzen and Tung (1976), Crook (1988) and Nappo (2013). We now discuss the ducting conditions in further detail. First, we need to verify the assumptions about a duct being present, this can be achieved using the following taken from the $2^{\text {nd }}$ term of the Taylor Goldstein equation (Nappo 2013) 


$$
Q(z)^{2}=\frac{N^{2}}{(c-U(z))^{2}}+\frac{\partial^{2} U}{\partial z^{2}} \frac{1}{(c-U(z))}-k_{H},
$$

where $U$ is the magnitude of the windspeed for a ducted wave and $z$ is height above the surface. $c$ and $k_{H}$ are constant with height as shown in Gill (1982). If $Q^{2}>0$, then ducting conditions are present. A profile of $Q^{2}$ is plotted in figure 1c for April 2011 which shows that $Q^{2}$ is positive from $500 \mathrm{~m}$ to approximately $3.5 \mathrm{~km}$ implying the presence of a wave duct over IS17.

Lindzen and Tung (1976) state a relationship between the depth of the duct $H$ and the vertical wavelengths $\lambda_{m}$ that can be supported with in it using the following

$$
\frac{H}{\lambda_{m}}=\frac{1}{4}+\frac{n}{2}, \quad n=0,1,2, \ldots
$$

where $n$ are the possible nodes. For $n=0, \lambda_{m}$ can be four times the width of the duct. Lindzen and Tung (1976) state that gravity waves with $\lambda_{m}$ that fit the lower order nodes dominate, whilst those that fit the higher order nodes tend to dissipate quickly due to the smaller spatial scales. Figure 2 shows a PDF of $\lambda_{m}$ calculated for the IS17 dataset using equation 4. Dashed lines indicate the vertical wavelengths dictated by node number using equation 6 for a duct where $\mathrm{H}=3 \mathrm{~km}$ thick as shown in figure 1c. Agreement is seen between the peak in $\lambda_{m}$ at $\sim 2400 \mathrm{~m}$ and the $n=2$ node. This further indicates the presence of ducted gravity waves above IS17. The findings here are similar to those in Crook (1988) who found gravity wave ducts in similar meteorological conditions to those seen here.

The values $\phi, c, \widehat{c}, \widehat{\omega}, p^{\prime}, k_{H}$ and $u$ ' were calculated from the IS17 gravity wave bulletin for the years between 2007 and 2011 and are analysed in sections 4 and 5. There is good data availability over this period. However, there is a gap in observations in February 2008.

\section{Lightning observations as a proxy for convection over IS17}

To explore the relationship between convective systems and the gravity waves observed at IS17 a method of inferring the time and location of the convection is needed. Convective systems can be observed using weather radar, daily precipitation measurements or by examining lightning strike data. Daily precipitation measurements and weather radar observations are limited over Africa, which moves the emphasis in observing convection in this region to remote sensing methods. For example, the Tropical Applications of Meteorology using SATellite and ground based observations (TAMSAT) (Maidment et al 2014) and Tropical Rainfall Measurement Mission (TRMM) (Kummerow et al 1998) use satellite based measurements to infer rainfall estimates. However, rainfall does not always imply convection so this method has limitations in inferring convection. The TRMM satellite was also equipped with a Lightning Imaging Sensor (LIS), however the scanning pattern for this sensor limits the temporal and spatial sampling resolution. An alternative to measuring lightning strikes from orbit is to use a terrestrial radio detection system, such as a Very Low Frequency (VLF) radio time arrival differencing system. Lightning strikes produce a broadband electromagnetic wave (or sferic) which can be detected by a radio antenna 1000s $\mathrm{km}$ from the lightning strike. By having multiple antennas spaced across the globe the position of each lightning strike can be inferred by examining the arrival time of the same sferic at each antenna. The UK Met Office's Arrival Time Difference network (ATDnet) allows lightning detection over Europe, the Atlantic and much of Africa (Nash et al 2006). ATDnet records lightning strikes as they occur with an accuracy of $\pm 50 \mathrm{~km}$ giving excellent temporal and spatial resolution. A significant limitation on this approach is that lightning serves only as a proxy for convection; non-electrically active convection may also occur which does not yield detectable lightning. 
ATDnet data for lightning strikes were bounded by the geographical region bounded by $10^{\circ} \mathrm{S}$ to $20^{\circ} \mathrm{N}$ and $20^{\circ} \mathrm{W}$ to $10^{\circ} \mathrm{E}$, an area centered on IS17, for the years 2007 to 2011 . This period was chosen to match gravity wave bulletins availability. Composite two-dimensional histograms with $0.25^{\circ}$ degree resolution were created from the subset of lightning data for each month of the year. Figure 3 shows 2D histograms for the months of January April, July and October using data from the ATDnet system. The ITCZ is apparent as a strip of thunderstorms which shifts to the north in the summer and south in Northern Hemispheric winter. To understand further how the position and distance of the thunderstorms changes with the gravity wave parameters the polar co-ordinates of each lightning strike, relative to IS17 are calculated and are retained for further analysis.

\section{Seasonal and daily analysis of GW parameters at IS17}

The analysis methodology given in section 2 was applied to the IS17 gravity wave bulletins between 2007 and 2011. The study period here is a smaller subset of that shown in Blanc et al (2014) which spanned 10 years. This is because both meteorological data and gravity wave detections are only available between 2007 and 2011.

Figure 4 and 5 shows boxplots of each derived parameter binned by 30-day periods to highlight the seasonal variations. Panel 4 a reproduces the annual variation in $\phi$ shown in Blanc et al (2014), and there are also clear annual variations in $p^{\prime}$ and $u^{\prime}$, panel $4 \mathrm{c}$ and $5 \mathrm{~b}$ respectively. There is evidence to suggest biannual variation in parameters $\hat{c}, \widehat{\omega}$ and $k_{H}$ in panels $4 \mathrm{~b}, 4 \mathrm{c}$ and $5 \mathrm{~b}$ respectively. This is likely due to the ITCZ passing over IS17 twice a year. Lightning strike distance is plotted in panel $5 \mathrm{~d}$, this was calculated by selecting lightning strikes that had a bearing which fell within the interquartile range of the gravity wave $\phi$ for each 30-day period. It also exhibits annual variation, where the median distance peaks at an average of $1300 \mathrm{~km}$ in December and January when the ITCZ, shown in figure $3 \mathrm{a}$ is more distant. The median distance is at a minimum when the ITCZ passes from north to south in September. Panel 5c shows there are about 300 gravity waves detected a month, which equates to 10 gravity waves passing over the station daily, in agreement with Blanc et al (2014).

To further explore the periodicities in each gravity wave parameter a Lomb periodogram (Lomb 1976) is created. The Lomb periodogram method is chosen as it can calculate the periodicities from irregularly sampled time series, as is the case for the gravity wave detection times. Due to the $\sim 10^{4}$ observations, the fast Lomb routine shown in Press (2007) is implemented.

Figure 6 shows Lomb periodograms for gravity wave parameters detected at IS17 during the study period. All parameters except $k_{H}$ show an annual periodicity, with all parameters also showing a 6-month periodicity, which further supports the hypothesis that gravity wave parameters are being modulated by the seasonal variations in ITCZ's position, which passes over IS17 twice a year. Furthermore, there are also daily periodicities shown for all gravity wave parameters in figure 6 , these will be further investigated in section 5 . To extract the annual and bi-annual periodicities found in figures 4 and 5 more effectively, annual composites have been computed for each gravity wave parameter, which are shown in figure 7.

Figure $7 \mathrm{a} /$ shows the annual variation in $\phi$ which shifts from a southerly direction in December to an easterly direction during April to June. The stalling during this period is likely due to the pre-onset stages of the West African Monsoon, which causes the ITCZ to 
stall at $5^{\circ} \mathrm{N}$, IS17's latitude in May and June (Sultan and Janicot, 2003), before reaching full intensity and moving north in August. Gravity wave $\phi$ continues to shift to a northerly direction during July and August before, backing back to an easterly direction in September. This is due to the ITCZ shifting southwards, heading into southern hemispheric summer. This agrees with the findings in Blanc et al (2014). Although convection and gravity wave generation occur in a broad band on either side of IS17 due to the ITCZ, the majority of gravity waves observed here have a component from an easterly direction. This is because winds over IS17 are predominantly from an easterly direction (Hart 1977) causing the propagation of gravity waves in a westward direction. Figure 1 shows the annual mean horizontal wind profile over IS17, centred at $4 \mathrm{~km}$ in altitude is an easterly jet which forms part of the ducting mechanism (Lindzen and Tung 1976, Nappo 2013) for the gravity waves observed here as suggested in section 2.

Figure $7 \mathrm{~b}$ shows the annual variation in $\hat{c}$, during December, January and August, $\hat{c}$ is larger during the equinox months, indicating when the ITCZ is more distant the $\hat{c}$ of observed gravity waves is higher. Given that the gravity waves have propagated further to reach IS17, there is likely to be more gravity wave attenuation along the path. Attenuation occurs due to interactions in the background flow, such as turbulent dissipation or wave-wave interactions (Fritts \& Alexander 2003). Figure $7 \mathrm{~g}$ shows that gravity wave detections are lowest in January-February and August when the ITCZ is most distant implying GW attenuation. As well as attenuation the top of the gravity wave duct is unlikely a perfect reflector and some of GW energy may pass through and propagate into the upper atmosphere. Secondly Gill (1982) states that slower waves have shorter wavelengths (larger $k_{H}$ ) than faster waves with longer wavelengths (small $k_{H}$ ), this is also shown in figure $7 \mathrm{e}$ where $k_{H}$ is smaller when the ITCZ is more distant, this is also reflected in $\widehat{\omega}$ shown in figure $7 \mathrm{~d}$. Thus, for more distant thunderstorm sources, faster gravity waves are observed.

Figure 7c shows the annual variation of the pressure amplitude of the wave $p^{\prime}$. When the ITCZ is overhead $p$ ' is larger, indicating that as the GW travel further their $p$ ' decreases, meaning the amplitude of the wave becomes smaller for more distance wave sources. The horizontal velocity perturbation $u$ ' also follows this trend. De Groot Hedlin (2017) state that in their studies slower GW were associated with larger $p$ '. Combining this with the fact that shorter wavelength waves are more strongly attenuated this explains the decrease in $p$ ' with propagation distance. As well as distance from the IS station, further consideration should be given to how the convective intensity may affect the gravity wave parameters. Beres et al (2004) showed that gravity wave spectra vary with the convective source. Figure 3 shows that convective intensity is weakest in December and January. Average monthly lightning counts, used here as a proxy for convective intensity, are plotted alongside monthly averages of gravity wave parameters and are shown in figure $\mathrm{S} 1$. Decreases in $p^{\prime}$ and increases in $\hat{c}$ in December January could have contributions from reduced convective activity in addition to the long distance the gravity waves have to propagate. However, it is hard to isolate the effects on intensity from the more prominent signal from propagation distance.

In summary, as the ITCZ becomes more distant from IS17 we see a reduction in the amount of gravity waves and that the gravity waves that are detected tend to have longer wavelengths, lower $\widehat{\omega}$ and $k_{H}$ and larger $\hat{c}$ which is likely due to attenuation of gravity waves with smaller $\hat{c}$. As the shorter GWs are not present this also causes a decrease in the size of $p$ ' and $u$ ' with distance from the ITCZ in the background flow. Here an explanation for the seasonal variation in gravity wave parameters has been discussed. In the next section, the daily variations in gravity wave activity are explored. 


\section{Daily variations}

It has been established that the position and distance of thunderstorms in the ITCZ relative to IS17 modulate the properties of gravity waves observed on seasonal time scales, it was also shown in figure 6 that a daily periodicity is present in the derived gravity wave parameters. It is likely that aspects of the convective diurnal cycle are being observed within the gravity wave parameters.

Before examining the daily variation in gravity wave parameters, it is important to understand the local convective cycle first. Figure 8 shows $2 \mathrm{D}$ histograms of lightning strikes by hour of day for April between 2007 and 2011. It can be seen between 3UT and 12UT (8b-8e) most thunderstorms occur over the ocean. Between 15UT and 0UT (8f-8a) most thunderstorms occur over the land, implying two distinct convective cycles which could be the source of the daily variation seen in figure 4. Figures S2 and S3 show 2D histograms of lightning strikes between 2007 and 2011 for July and December respectively. Figure 9 shows total lightning strikes plotted by hour of the day for the months April, July and December for the subset area described in section 3. Also plotted are the total lightning strikes over land and over ocean. It can be seen in all three plots that the lightning strike intensity over the oceans peaks between 6UT and 9UT whereas lightning activity over land peaks between 14UT and 21UT. The relative contribution from the two convective regimes varies throughout the year and this is due to the position of the ITCZ, in December when the ITCZ is due south the ocean convective regime is dominant and in July the continental convective scheme is dominant when the ITCZ is due north.

Figure 10 shows the daily variation in the median and interquartile range of gravity wave parameters for April, July and December. It should be noted no data was available for the hours of 23UT to 0UT due to the processing method utilised which exhibits a wraparound issue around midnight. With the exception of $\phi$ all gravity wave parameters follow a similar pattern in daily variation throughout the year, the magnitude does however change, for example in panels $10 \mathrm{c}$ and $10 \mathrm{f}$ the $p^{\prime}$ and $u$ ' quantities are largest when the ITCZ is closest in April. Panel 10a shows $\phi$, for April (blue), between 18UT and 6UT there are GWs with $\phi$ propagating from the NE indicating they are from thunderstorms generated over land and between 6UT and 17UT, $\phi$ shifts to the SE, indicative of gravity waves propagating from ocean and coastal areas. Figure 9a shows that peak thunderstorm activity over the ocean occurs between 03UT and 12UT and peak thunderstorm activity occurs over land between 15UT and OUT. This lag of approximately 6 hours is due to the distance gravity waves have to travel which is also outlined in figure 5. $\phi$ for July (green), is from a NE direction between 20UT and 9UT, between 9UT and 19UT the $\phi$ begins to shift to a more E direction with increased variability indicating there may be a GW contribution from ocean convective sources. Figure $9 \mathrm{~b}$ shows that during July there is a small amount of ocean thunderstorm activity, which is also seen in figure S2 $700 \mathrm{~km}$ E of IS17 between 6UT and 12UT. The GW $\phi$ in December (red) remains constant from the SE, there is some increased variability between 6UT and 13UT indicating there may be a small contribution from thunderstorms over land from the previous day, as shown in figure 9c and in figure S2.

In panel 10b all months show a peak in $c_{i}$ between 15UT and 18UT. the peak here is likely due to the detection of gravity waves in very close proximity to IS17. In all three months, lightning maps show thunderstorms form overhead ITCZ and it is likely the fast waves are detected here before they become affected by the background flow. Panel 10e, shows that $k_{H}$ is shorter for April and December during these times, which agrees with theory. Panel 10c shows $p$ ' in April and December peaks between 9UT and 12UT which is also when $\hat{c}$ was 
found to be slowest in panel 10b, agreeing with de Groot Hedlin (2017). This is also apparent in $u^{\prime}$, in panel 10f. $\widehat{\omega}$ was found to have near identical minimums for all months between 10UT and 14UT, during other times there are differences between the months. This is likely due to changes to the detection performance of the infrasound array and processing algorithm, since turbulent noise is larger in the boundary layer in the middle of the day and degrades detection performance.

Figure 11 shows a histogram of detections by day which also shows a dip in the amount of gravity wave detections being made during the middle of the day. This may distort the results for all parameters apart from $\phi$ as only gravity waves with the largest pressure amplitudes, and hence lower $\hat{c}$ and larger $k_{H}$, will be observed. Furthermore, by observing the lightning activity in figures 8 and 9 there should be many gravity waves passing the array now due to the nearby ocean driven convection that occurs in the first half of the day. This implies there is a potential bias to slower gravity waves, with larger $k_{H}$ and $p$ ' in the middle of the day.

In summary, $\phi$ is heavily modulated by the daily position of convection around IS17 which occurs over ocean in the morning and over land in the mid-afternoon and early evening. $\hat{c}$ also exhibits a daily variation, which whilst some components such as the peak at 15UT to 18UT are due to localised convection, which other parameters show agreement with. There is the potential that the diurnal variation is amplified for wave parameters due to the bias in the ability of the array to detect waves with smaller $p$ ' during the middle of the day.

\section{Conclusions}

A detailed analysis of ducted gravity waves observed at the Ivory Coast Infrasound station (IS17) has been undertaken, with an emphasis on establishing their source regions. This work expands on Blanc et al (2014), by including meteorological parameters, the use of a spectral analysis to demonstrate annual and daily periodicities in $\widehat{\omega}, \hat{c}, p^{\prime}, k_{H}$ and $u^{\prime}$ and exploring these periodicities with Met Office ATDnet lightning strike data over the region. When the ITCZ was furthest from IS17 during the summer and winter months, there is a decrease in the number of detected gravity waves. The gravity waves which were observed had smaller $p$ ' and larger $\hat{c}$ due to gravity wave attenuation, due to the increased propagation distance between the sources, thunderstorms in the ITCZ, and the IMS station.

The spectral analysis also revealed a daily variation in all GW parameters, which was analysed alongside lightning strike data on daily time scales for the months April, July and December. From the lightning strike data, it was found that two convective cycles were present. The first of these, over the ocean, peaked between 03UT and 12UT, and the second, over land, peaked between 15UT and 21UT. The gravity wave back azimuth was found to be sensitive to these different convective regions, with the back azimuth showing peak gravity wave propagation approximately 6 hours after peak lightning activity was observed for each region. The strongest change in $\phi$ was during April when the ITCZ was overhead. Given the distance shown in figure $7 \mathrm{~g}$, this would imply a propagation speed of $\sim 50 \mathrm{~m} \mathrm{~s}^{-1}$.

Other gravity wave parameters were found to follow similar patterns throughout the day as the times of the convective regimes don't vary much just their intensity. This resulted in a peak in $\hat{c}$ between 15UT and 18UT when the fastest gravity waves generated by thunderstorms directly adjacent to the array are observed, and, during this time interval, larger wavelength waves were also detected. It is suspected due to noise interference due to turbulence in the middle of the day faster gravity waves, with smaller $p$ ' are not detected. As this has a follow-on effect for the other gravity wave parameters in that this amplifies the diurnal variation detected in the spectral analysis. 
Analyses such as this, provide a useful tool into understanding further how gravity waves are emitted from convective sources. Most modelling cases and parametrisations concentrate on the vertical propagation of gravity waves into the middle atmosphere (e.g. Kim et al (2003), Beres et al (2004), Richter et al (2010) and Lott \& Guez (2013)) and seldom on trapped waves. This is because the momentum flux within the duct is near zero. However, the upper edge of the gravity wave duct is not a perfect reflector and some gravity wave momentum flux is released (Gill 1982, Nappo 2013, Marlton et al 2018) potentially releasing momentum flux far from the convective source. Studies such as de Groot-Hedlin (2017) have shown agreement between stratospheric measurements of gravity waves and ground based measurements, allowing a global infrasound network such as the IMS to provide a proxy for stratospheric GW measurements.

\section{Acknowledgments, Samples, and Data}

This work was performed during the course of the ARISE2 collaborative infrastructure design study project funded by the European Commission H2020 program (grant number 653980, arise-project.eu). The Authors would like to acknowledge Station Géophysique de Lamto in Ivory Coast for their work in maintaining the IS17 infrasound station. The French Atomic Energy Commission (CEA) for the processing and provision of the infrasound and meteorological data from IS17. The gravity wave climatology is available to download from the University of Reading's data repository at: DOI to be added when available. The UK Met Office ATDnet data was provided by Sven-Eric Enno and is available on request. Model data from the ECMWF is available through the ECMWF's MARS archive.

\section{References}

Aplin, K.L. and Harrison, R.G., (2003), Meteorological effects of the eclipse of 11 August 1999 in cloudy and clear conditions. Proceedings of the Royal Society of London A: Mathematical, Physical and Engineering Sciences, 459, 353-371, doi: https://doi.org/10.1098/rspa.2002.1042

Balachandran N.K., Gravity waves from thunderstorms., (1980), Monthly weather review, 108(6), 804-816,doi: https://doi.org/10.1175/1520-0493(1980)108<0804:GWFT>2.0.CO;2

Beres, J.H., Alexander, M.J. and Holton, J.R., (2004), A method of specifying the gravity wave spectrum above convection based on latent heating properties and background wind. Journal of the atmospheric sciences, 61(3), 324-337, doi: https://doi.org/10.1175/15200469(2004)061<0324:AMOSTG>2.0.CO;2

Blanc, E., Farges, T., Le-Pichon, A. and Heinrich, P., (2014), Ten year observations of gravity waves from thunderstorms in western Africa, Journal of Geophysical Research: Atmospheres, 119(11), 6409-6418, doi: 10.1002/2013JD020499

Cansi, Y., (1995), An automatic seismic event processing for detection and location: The PMCC method, Geophysical Research Letters, 22(9), 1021-1024, doi: 10.1029/95GL00468

Chimonas, G. and Hines, C.O., (1986). Doppler ducting of atmospheric gravity waves, Journal of Geophysical Research: Atmospheres, 91(D1), pp.1219-1230, doi: 10.1029/JD091iD01p01219

Christie, D.R. and Campus, P., (2010). The IMS infrasound network: design and establishment of infrasound stations. Infrasound monitoring for atmospheric studies, 29-75 
Crook, N.A., 1988. Trapping of low-level internal gravity waves. Journal of the atmospheric sciences, 45(10), pp.1533-1541.

Dahlman, O., S. Mykkeltveit, and H. Haak (2009), Nuclear Test Ban: Connecting Political Views to Reality, Springer, pp. 113-142, Netherlands.

de Groot-Hedlin, C. D., Hedlin, M. A. H., Hoffmann, L., Alexander, M. J., \& Stephan, C. C., (2017). Relationships between gravity waves observed at the Earth's surface and in the stratosphere over the central and eastern United States. Journal of Geophysical Research:Atmospheres, 122. https://doi.org/10.1002/2017JD027159

Evers, L.G., (2008), The inaudible symphony: on the detection and source identification of atmospheric infrasound, TU Delft, Delft University of Technology

Farges, T., Le-Pichon, A., Blanc, E., Perez, S. and Alcoverro, B., (2003), Response of the lower atmosphere and the ionosphere to the eclipse of August 11, 1999, Journal of Atmospheric and Solar-Terrestrial Physics, 65(6), 717-726, doi: https://doi.org/10.1016/S1364-6826(03)00078-6

Fritts, D.C and Alexander, M.J, (2003), Gravity wave dynamics and effects in the middle atmosphere, Reviews of Geophysics, 41(1), doi: 10.1029/2001RG000106

Geller, M.A., Alexander, M.J., Love, P.T. Bacmeister, J., Ern, M., Hertzog, A., Manzini, E., Preusse, P., Sato, K., Scaife, A.A and others, (2013), A comparison between gravity wave momentum fluxes in observations and climate models, Journal of Climate, 26(17), 6383-6405, doi: https://doi.org/10.1175/JCLI-D-12-00545.1

Gill, A.E., (1982), Atmosphere-Ocean dynamics, Academic Press,

Hart, J.E., 1977. On the theory of the East African low-level jet stream. pure and applied geophysics, 115(5-6), pp.1263-1282. Doi: https://doi.org/10.1007/BF00874409

Jacques AA, Horel JD, Crosman ET, Vernon FL., (2015) Central and eastern US surface pressure variations derived from the USArray network. Monthly Weather Review, 143(4), 1472-93, doi: https://doi.org/10.1175/MWR-D-14-00274.1

Kim, Y.J., Eckermann, S.D. and Chun, H.Y., 2003. An overview of the past, present and future of gravity-wave drag parametrization for numerical climate and weather prediction models. Atmosphere-Ocean, 41(1), pp.65-98.

Knox, J.A., McCann, D.W., and Williams, P.D., (2008). Application of the Lighthill-Ford theory of spontaneous imbalance to clear-air turbulence forecasting. Journal of the Atmospheric Sciences, 65(10), pp3292-3304, doi: https://doi.org/10.1175/2008JAS2477.1

Kummerow, C., Barnes, W., Kozu, T., Shiue, J. and Simpson, J., (1998). The tropical rainfall measuring mission (TRMM) sensor package. Journal of atmospheric and oceanic technology, 15(3), pp.809-817, doi: $\underline{\text { https://doi.org/10.1175/1520- }}$ 0426(1998)015<0809:TTRMMT>2.0.CO;2

Le-Pichon, A., and Garces, M., Blanc, E., and Barthelemy, M. and Drob, D.P., (2002), Acoustic propagation and atmosphere characteristics derived from infrasonic waves generated by the Concorde, The Journal of the Acoustical Society of America, 111(1), 629-641, doi: https://doi.org/10.1121/1.1404434

Lindzen, R.S. and Tung, K.K., (1976), Banded convective activity and ducted gravity waves, Monthly Weather Review, 104(12), pp.1602-1617.doi: https://doi.org/10.1175/15200493(1976)104<1602:BCAADG>2.0.CO;2 
Lomb, N.R., (1976), Least-squares frequency analysis of unequally spaced data, Astrophysics and Space Science, 39(2), 447-462, doi: https://doi.org/10.1007/BF00648343

Lott, F., and L. Guez (2013), A stochastic parameterization of the gravity waves due to convection and its impact on the equatorial stratosphere, J. Geophys. Res. Atmos., 118, 8897-8909, doi:10.1002/jgrd.50705.

Maidment, R., Grimes, D., Allan, R., Tarnavsky, E., Stringer, M., Hewison, T., Roebeling, R., and Black, E. (2014). The 30-year TAMSAT African Rainfall Climatology and Timeseries (TARCAT) Data Set. Journal of Geophysical Research: Atmospheres, 119(10),61910,644. DOI: 10.1002/2014JD021927.

Marlton, G., A. Charlton-Perez, G. Harrison, and C. Lee (2018), Calculating atmospheric gravity waves parameters from infrasound measurements, in Infrasound monitoring for atmospheric studies: Challenges in middle-atmosphere dynamics and societal benefits, doi: 10.1007/978-3-319-75140-5, edited by A. L. Pichon, E. Blanc, and A. Hauchecorne, Springer Nature, Netherlands (in press).

Marty, J., D. Ponceau, and F. Dalaudier (2010), Using the International Monitoring System infrasound network to study gravity waves, Geophys. Res. Lett., 37, L19802, doi:10.1029/2010GL044181.

Melton, B. S., AND L. F. BAiley (1957), Multiple Signal CORRElators, Geophysics, 22, 565-588, DOI: 10.1190/1.1438390.

NAPPO, C.J., (2013), AN INTRODUCTION TO ATMOSPHERIC GRAVITY WAVES. Academic Press

Nash, J., Atkinson, N.C., Hibbett, E., Callaghan, G., Taylor, P.L., Odhams, P., Jenkins, D., Keogh, S., Gaffard, C. and Walker, E., (2006), The new Met Office ATDNET lightning detection system. In Proc. WMO Technical Conf. on Instruments and Observing Methods (Vol. 94).

Ponceau, D., and L. Bosca (2010), Low-noise broadband microbarometers, in Infrasound Monitoring for Atmospheric Studies, edited by A. Le Pichon, E. Blanc, and A. Hauchecorne, pp. 119 - 140, Springer, New York. chap. 4.

Press, W.H., Teukolsky, S.A., Vetterling, W.T. and Flannery B.P., (2007), Numerical recipes $3^{\text {rd }}$ edition: The art of scientific computing, Cambridge University Press

Richter, J.H., Sassi, F. and Garcia, R.R., (2010). Toward a physically based gravity wave source parameterization in a general circulation model. Journal of the Atmospheric Sciences, 67(1), 136-156. Doi: https://doi.org/10.1175/2009JAS3112.1

SMART, E., AND E. A. FLINN (1971), FAST FREQUENCY-WAVENUMBER ANALYSIS AND Fisher Signal DETECTION IN REAL-Time INFRASONIC ARRAY DATA PROCESSING, Geophys. J. Roy. Astron. Soc., 26, 279-284, DOI:10.1111/J.1365-246X.1971.TB03401.X.

Stein, T.H., PARKer, D.J., Hogan, R.J., Birch, C.E., Holloway, C.E., LiSTeR, G.M., MARSHAM, J.H. AND WOOLNOUGH, S.J., (2015), THE REPRESENTATION OF THE WEST AFRICAN MONSOON VERTICAL CLOUD STRUCTURE IN THE MET OFFICE UNIFIED MOdEL: AN EVAluATION WITH CloudSAT.Quarterly Journal of the Royal Meteorological Society, 141(693), PP.3312-3324. 
Sultan, B. and Janicot, S., (2003), The West African monsoon dynamics. Part II: The "preonset" and "onset" of the summer monsoon. Journal of climate, 16(21), 3407-3427, doi: https://doi.org/10.1175/1520-0442(2003)016<3407:TWAMDP>2.0.CO;2

Wallace, J.M. and Hobbs, P.V., (2006), Atmospheric science: an introductory survey (Vol. 92). Academic press.

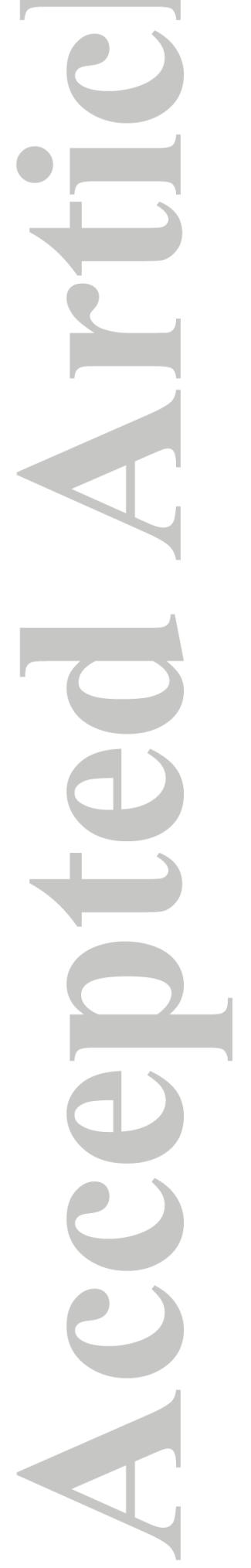




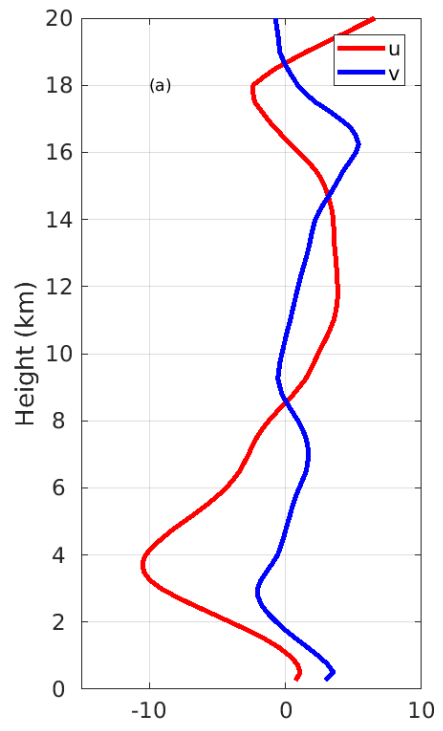

ECMWF mean wind component $\left(\mathrm{m} \mathrm{s}^{-1}\right)$
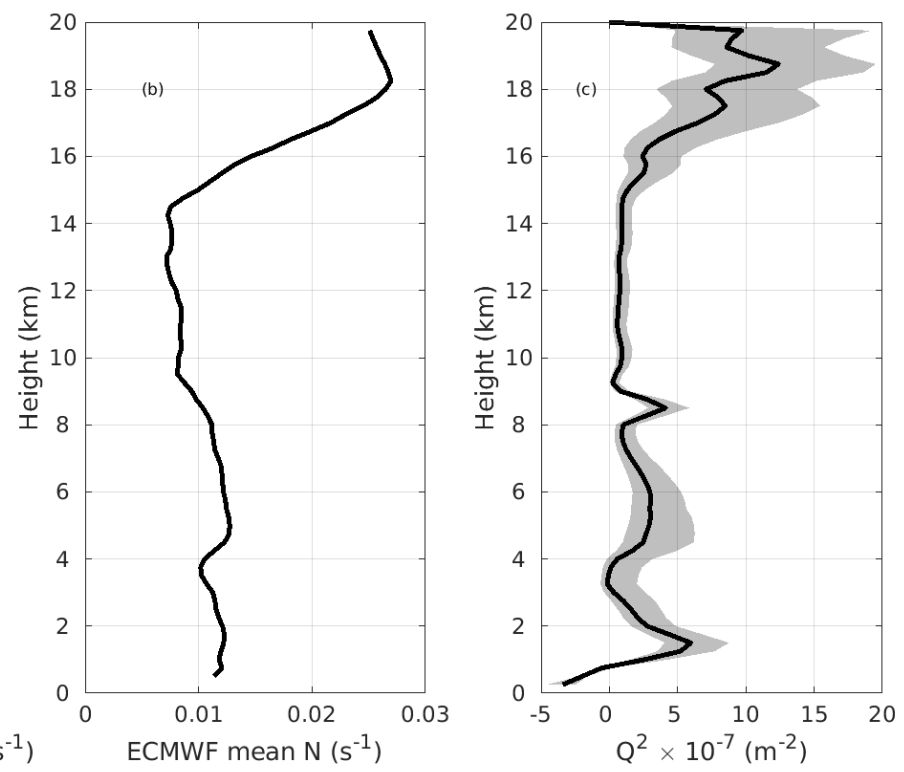

Figure 1: a) Vertical profiles of the mean $u$ (red) and $v$ (blue) wind component ( $\mathrm{m} \mathrm{s}^{-1}$ ) and b) mean $N\left(\mathrm{~s}^{-1}\right)$ over IS17, Ivory Coast derived from the ECMWF HRES model for April 2011. c) Vertical profile of the median $Q^{2}\left(\mathrm{~m}^{-2}\right)$ (solid line) and interquartile range shading. $Q$ is derived from the profiles in (1a and $1 \mathrm{~b}$ ) and from a distribution of gravity wave parameters $c$ and $k_{H}$ for April 2011. 


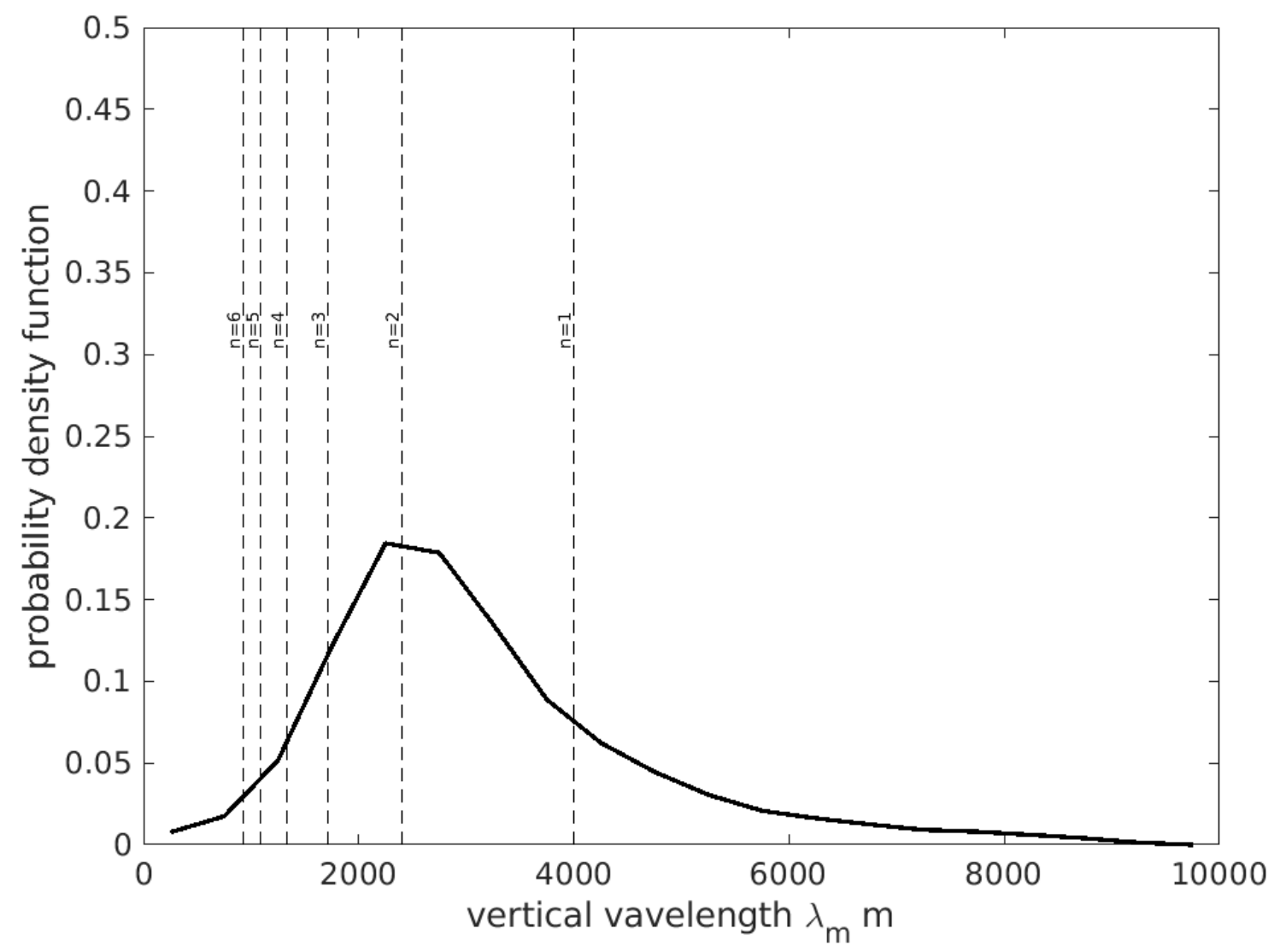

Figure 2: A probability density function of vertical wavelength $\lambda_{m}$ for gravity waves observed at IS17. The theoretical vertical wavelengths dictated for a duct of depth $3 \mathrm{~km}$ are shown for nodes $n=1$ to 6 . 

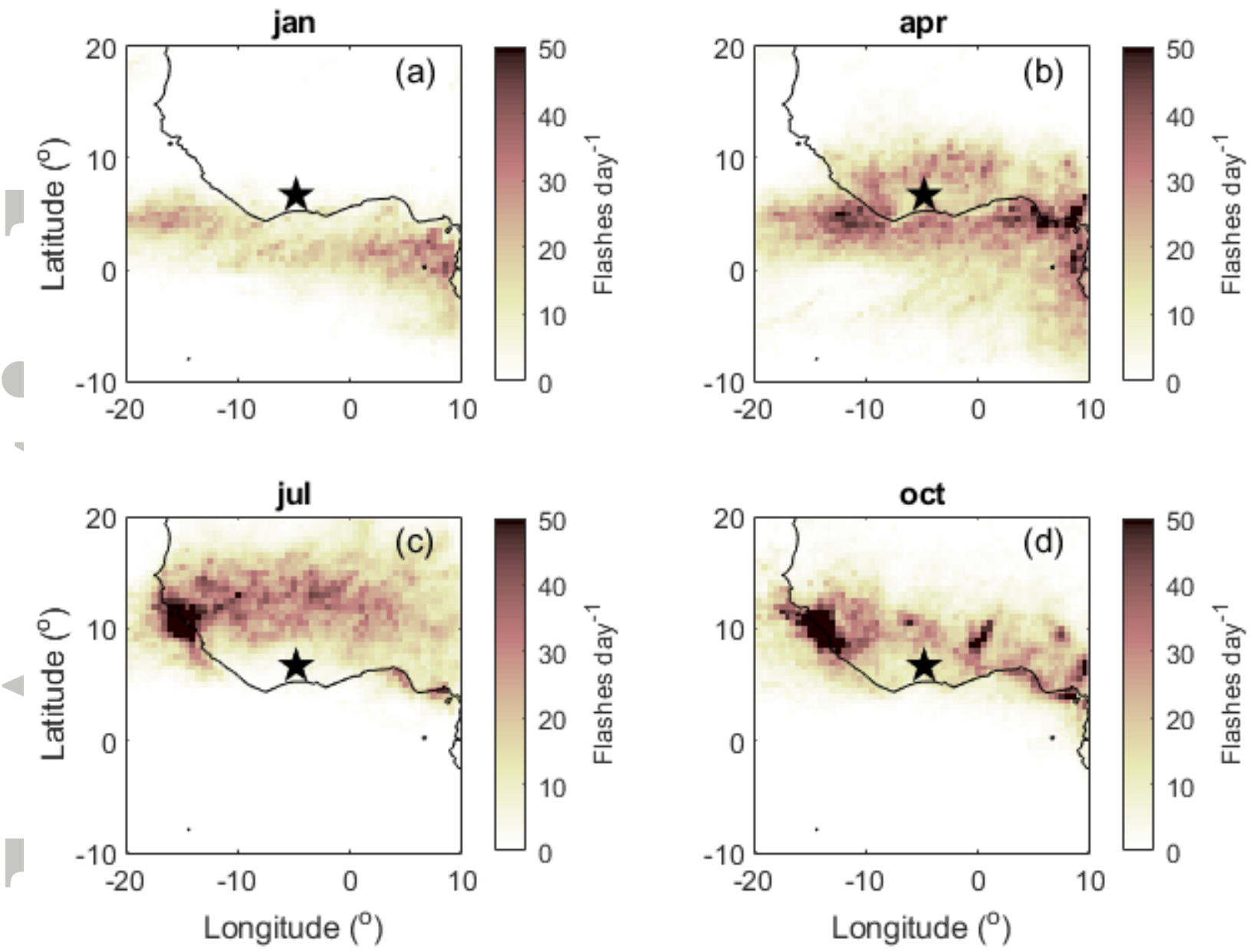

Figure 3: Lightning maps from the Met Office ATDnet system over western Africa for the months a) January, b) April, c) July and d) October for the years 2007-2011. The colors show the average flash rate per day. Black stars mark the position of infrasound station IS17, and the black outline shows the African coast. 

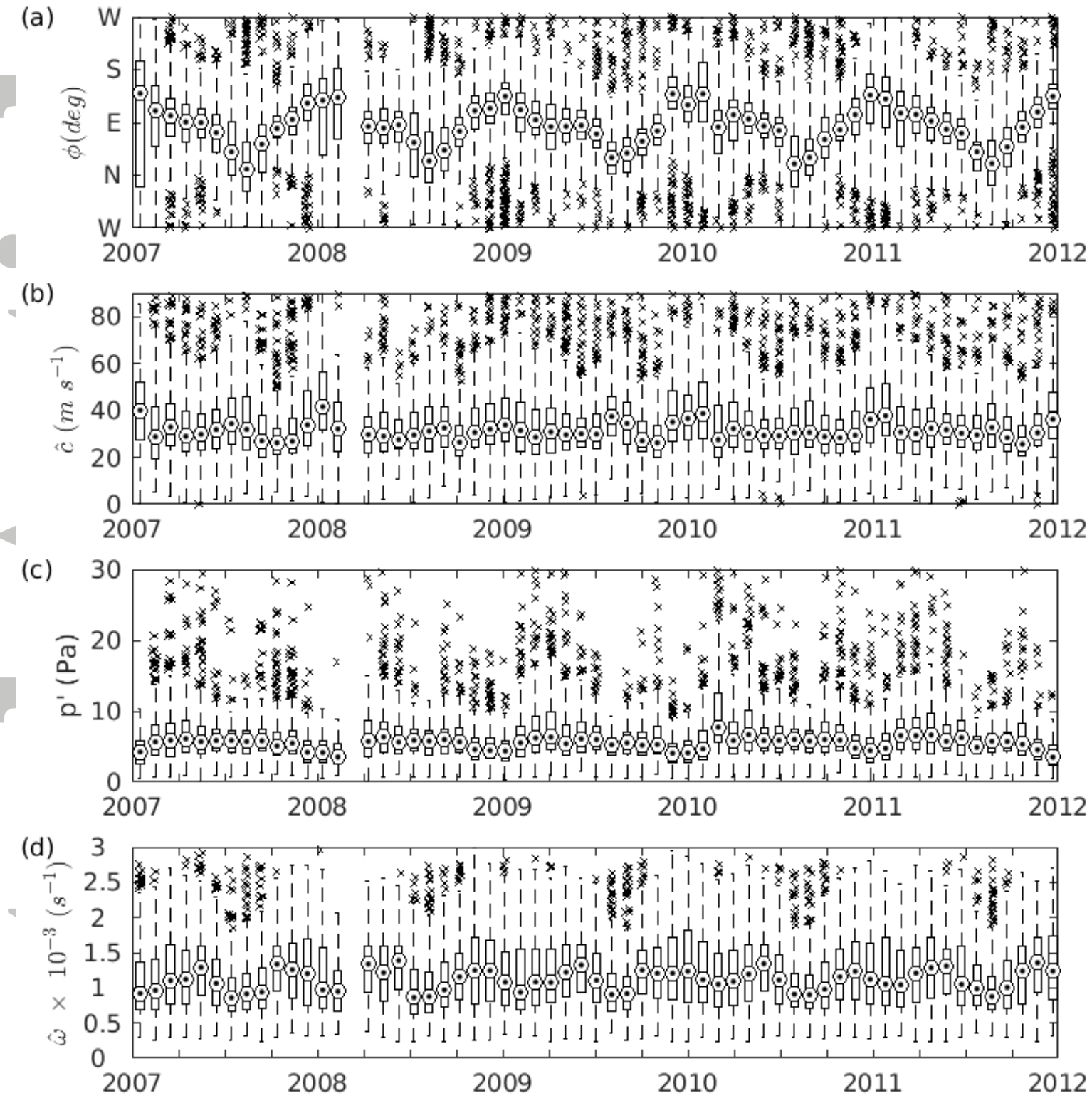

Figure 4: Boxplots of the gravity wave parameters: a) back azimuth $\phi$ (deg), b) intrinsic wave speed $\left.\hat{c}\left(\mathrm{~m} \mathrm{~s}^{-1}\right), \mathrm{c}\right)$ pressure perturbation $P^{\prime}(\mathrm{Pa})$ and d) intrinsic frequency $\widehat{\omega}\left(\mathrm{s}^{-1}\right)$. The dot within the circle is the median of the quantity, with the box representing the inter quartile range of the quantities. Upper black stems represent the lowest of either the 75th percentile plus one and a half times the interquartile range of the binned data or the maximum value of the binned data. Lower black stems represent the greatest of either the 25 th percentile minus one and a half times the interquartile range of the binned data or the minimum value of the binned data. Black crosses show outliers which are data points that fall outside range given by the black stems.) 
(a)

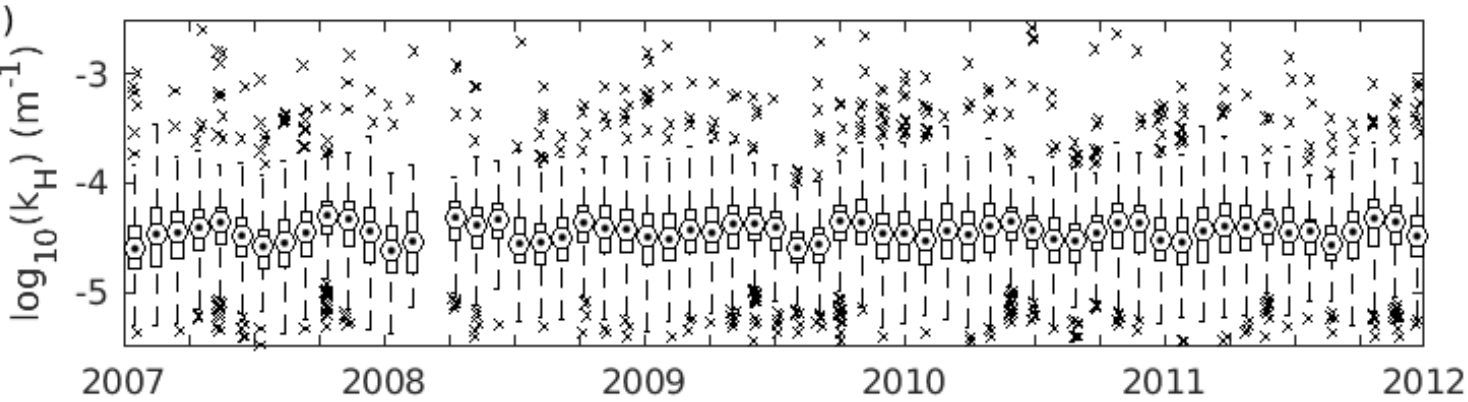

(b)
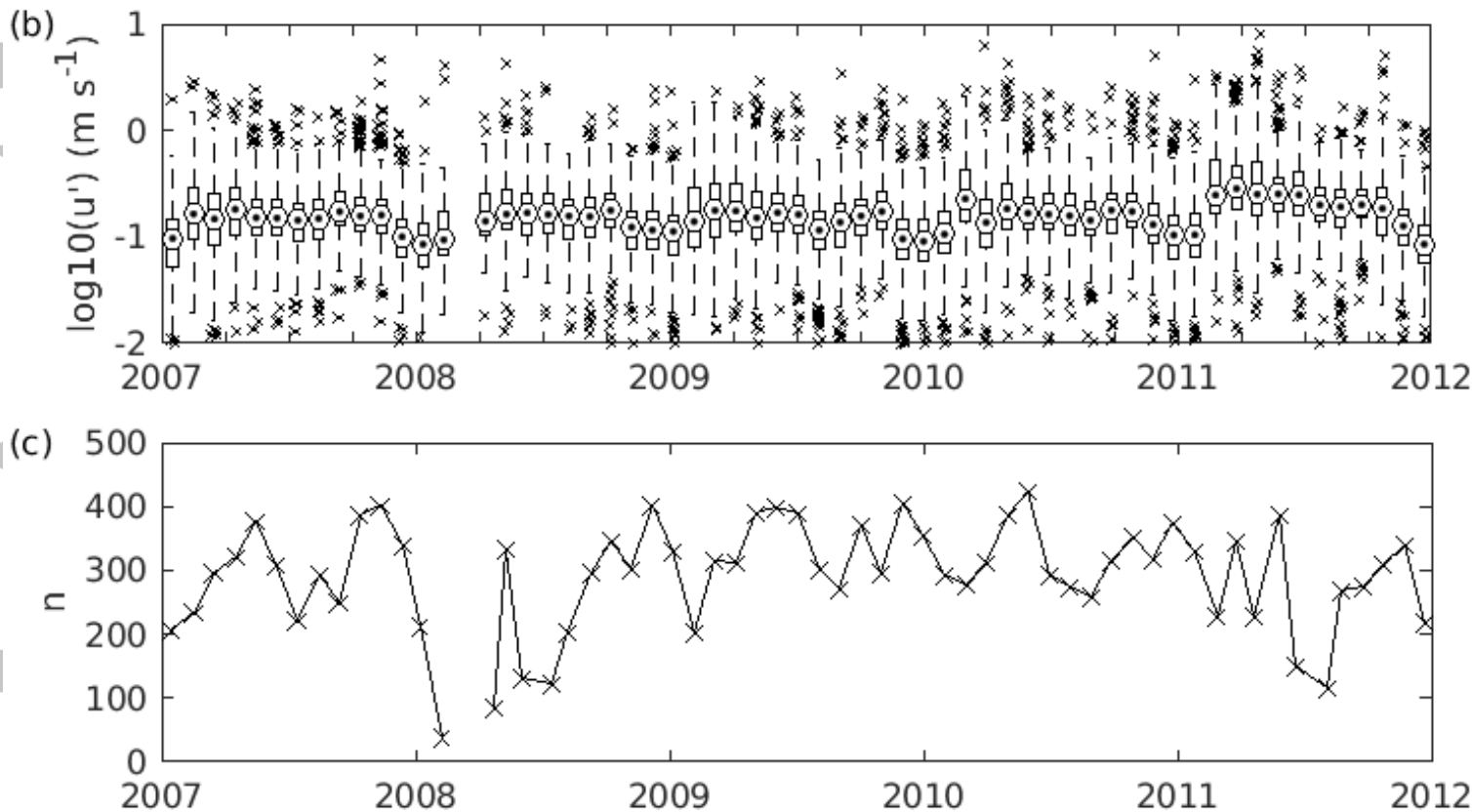

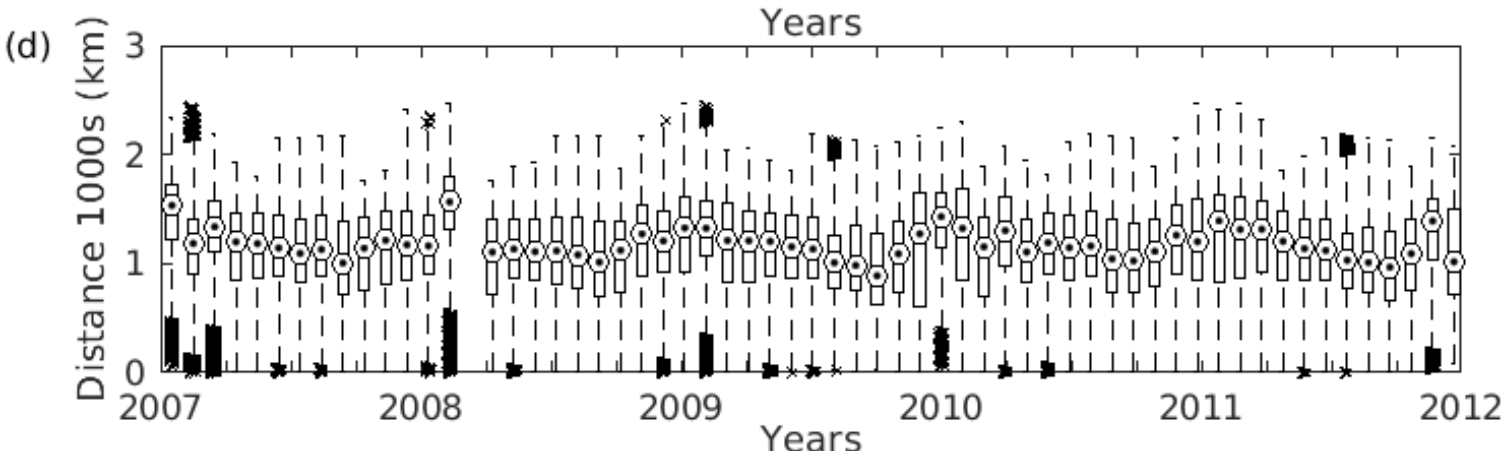

Figure 5 Boxplots of a) $\log _{10}$ horizontal wave number $k_{H}\left(\mathrm{~m}^{-1}\right)$, b) $\log _{10}$ horizontal velocity perturbation $\mathrm{u}^{\prime}\left(\mathrm{m} \mathrm{s}^{-1}\right)$ and $\left.\mathrm{d}\right)$ the distance in 1000s $\mathrm{km}$ of lightning strikes within the interquartile range of $\phi$ detected by Met Office ATDnet all binned over 30 day periods between 2007 and 2012 for IS17 (Ivory Coast). For boxplot meaning consult caption for figure 4. c) shows the number of gravity wave detections $n$ for each 30-day period at IS17. 

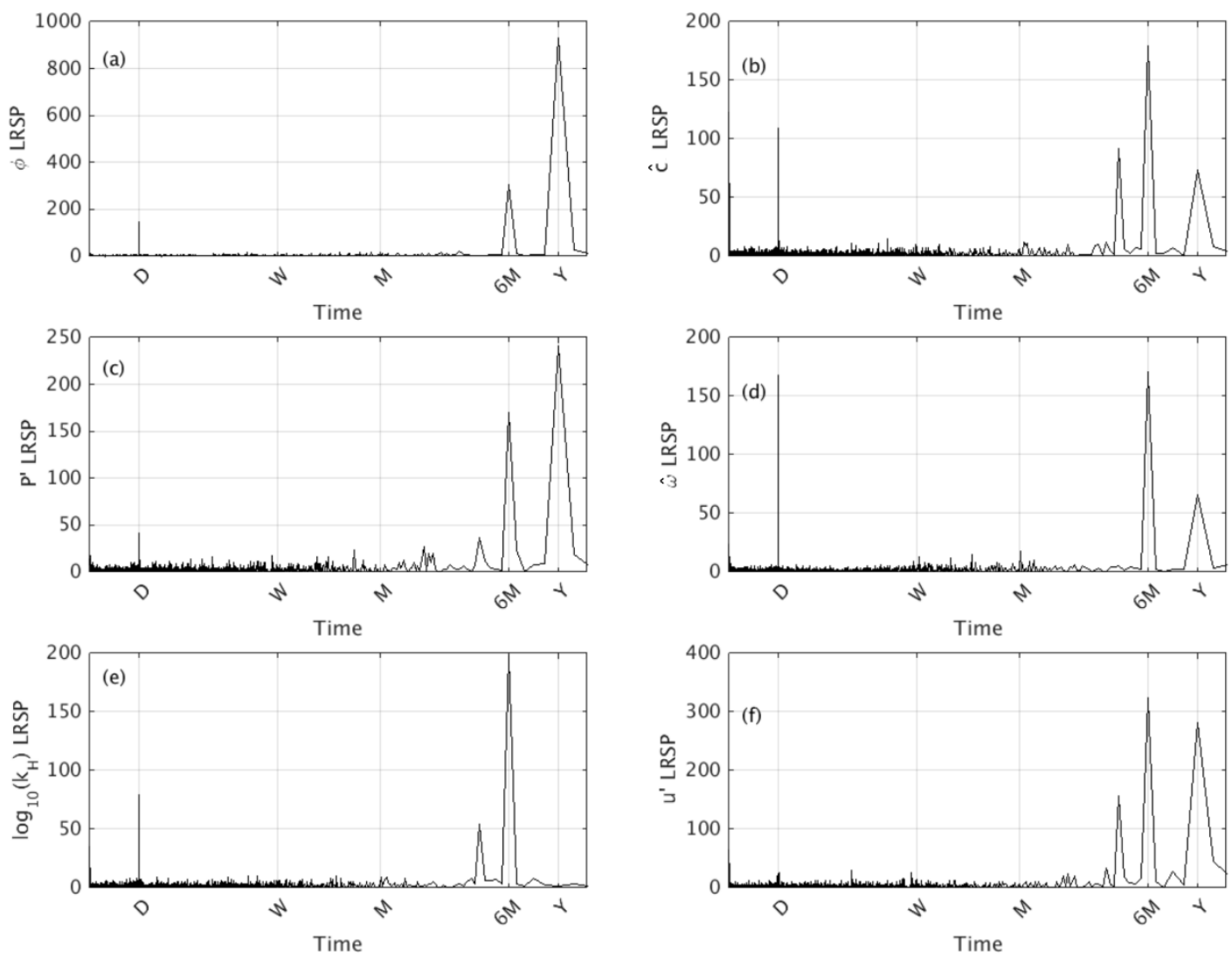

Figure 6: Lomb periodograms showing the Lomb Relative Spectral Power (LRSP) (dimensionless) for a) back azimuth $\phi(\mathrm{deg}), \mathrm{b})$ intrinsic wave speed $\left.\hat{c}\left(\mathrm{~m} \mathrm{~s}^{-1}\right), \mathrm{c}\right)$ pressure perturbation $\mathrm{P}^{\prime}(\mathrm{Pa})$, d) intrinsic frequency $\widehat{\omega}\left(\mathrm{s}^{-1}\right)$, e) $\log _{10}$ horizontal wave number $\mathrm{k}_{\mathrm{H}}\left(\mathrm{m}^{-1}\right)$ and $\mathrm{f}$ ) horizontal velocity perturbation $u^{\prime}\left(\mathrm{m} \mathrm{s}^{-1}\right)$ for gravity waves detected at IS17 between 2007 and 2011. The horizontal axis mark day (D), week (W), month (M), half year (6M) and year (Y) periodicities. 
(a)

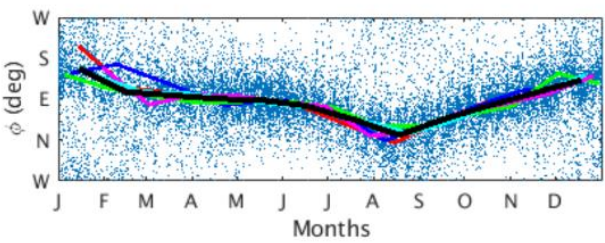

(c)
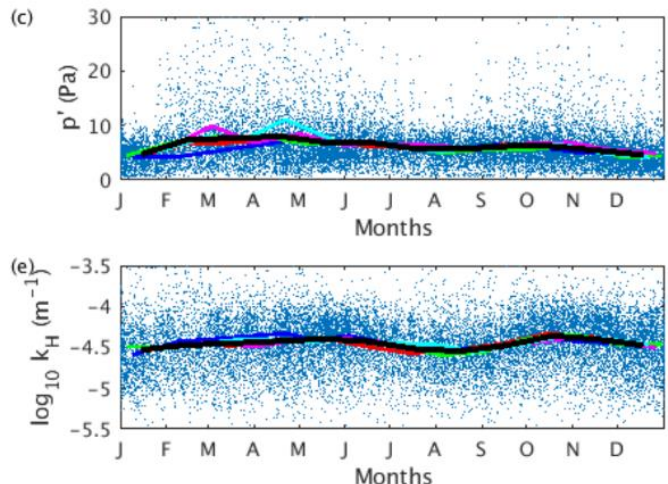

(g)

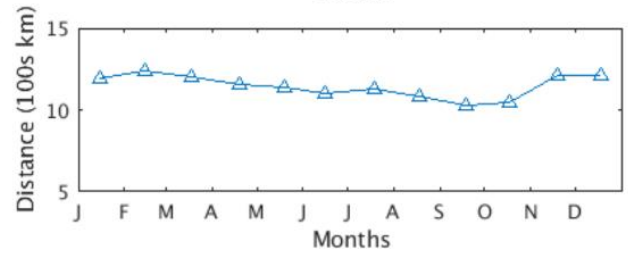

(b)

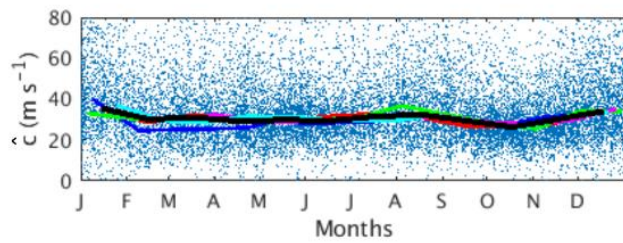

(d)
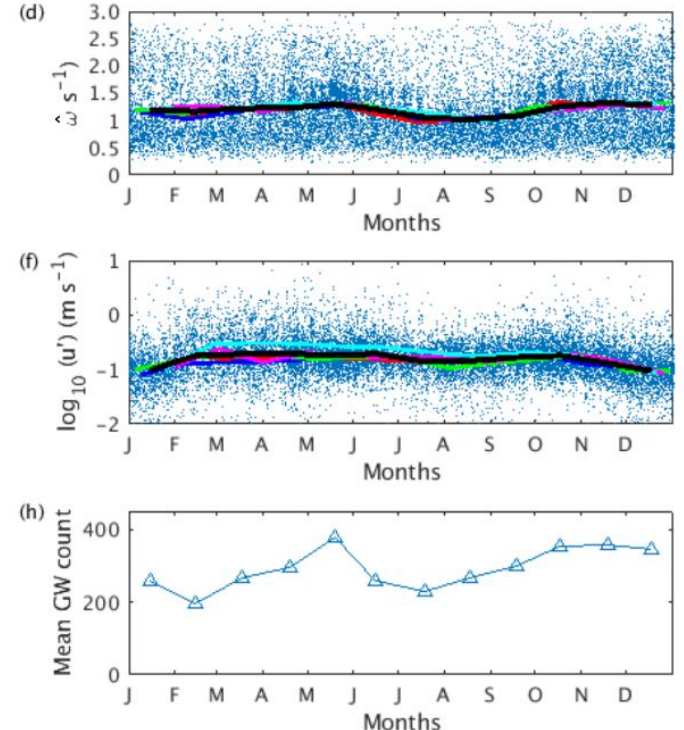

Figure 7: Annual composites of the gravity wave parameters: a) Back azimuth $\phi(\mathrm{deg}), \mathrm{b})$ intrinsic phase speed $\hat{c}\left(\mathrm{~m} \mathrm{~s}^{-1}\right)$, c) Pressure perturbation $\left.\mathrm{P}^{\prime}(\mathrm{Pa}), \mathrm{d}\right)$ intrinsic frequency $\widehat{\omega}\left(\mathrm{s}^{-1}\right)$, e) $\log _{10}$ horizontal wavenumber $\mathrm{k}_{\mathrm{H}}\left(\mathrm{m}^{-1}\right)$ and $\left.\mathrm{f}\right) \log _{10}$ of the vertical velocity perturbation $\mathrm{w}$, $\left(\mathrm{m} \mathrm{s}^{-1}\right)$. Red, blue, green, magenta and cyan lines are monthly averages for 2007 to 2011 respectively. The black line is the monthly average over those years. Panels $g$ and h show the monthly average GW count and lightning strike distance, along a sector defined by the angular range equating to the interquartile range of $\phi$ for 2007 to 2011 respectively. 

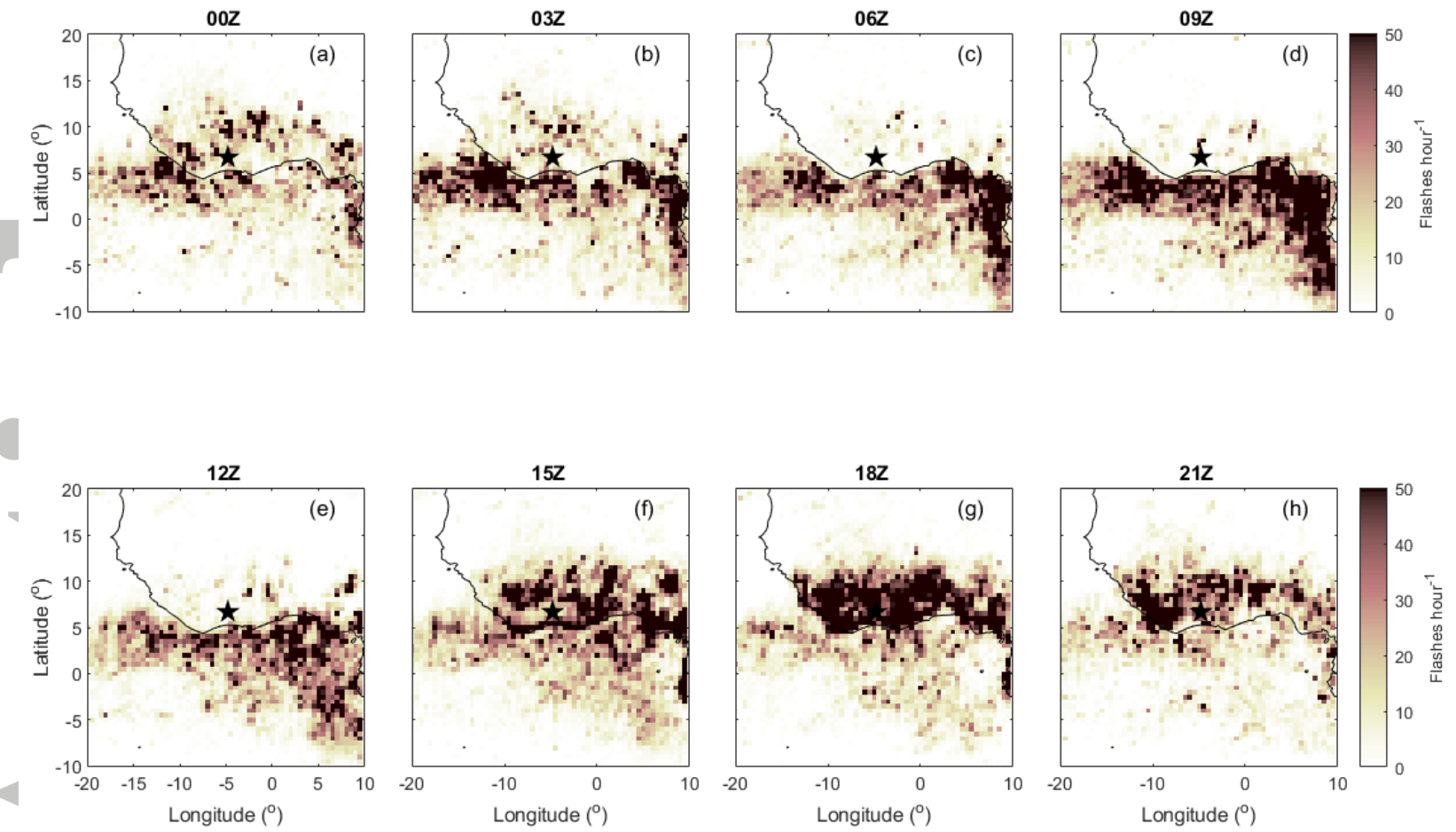

Figure 8: Flash rates of lightning strikes detected by the Met Office ATDnet over western Africa for lightning strikes that occurred at 0UT, 3UT, 6UT, 9UT, 12UT, 15UT, 18 UT and $21 \mathrm{UT}$, a-h respectively during the month of April in the years 2007-2011. (The coast outline is marked in black and the position of IS17 is marked by a black star).

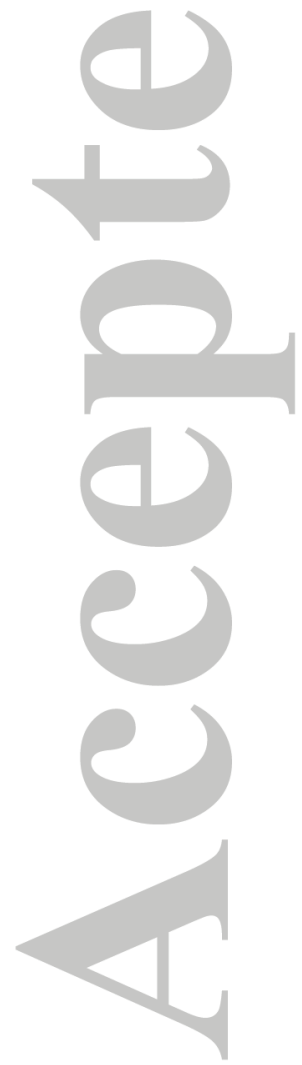



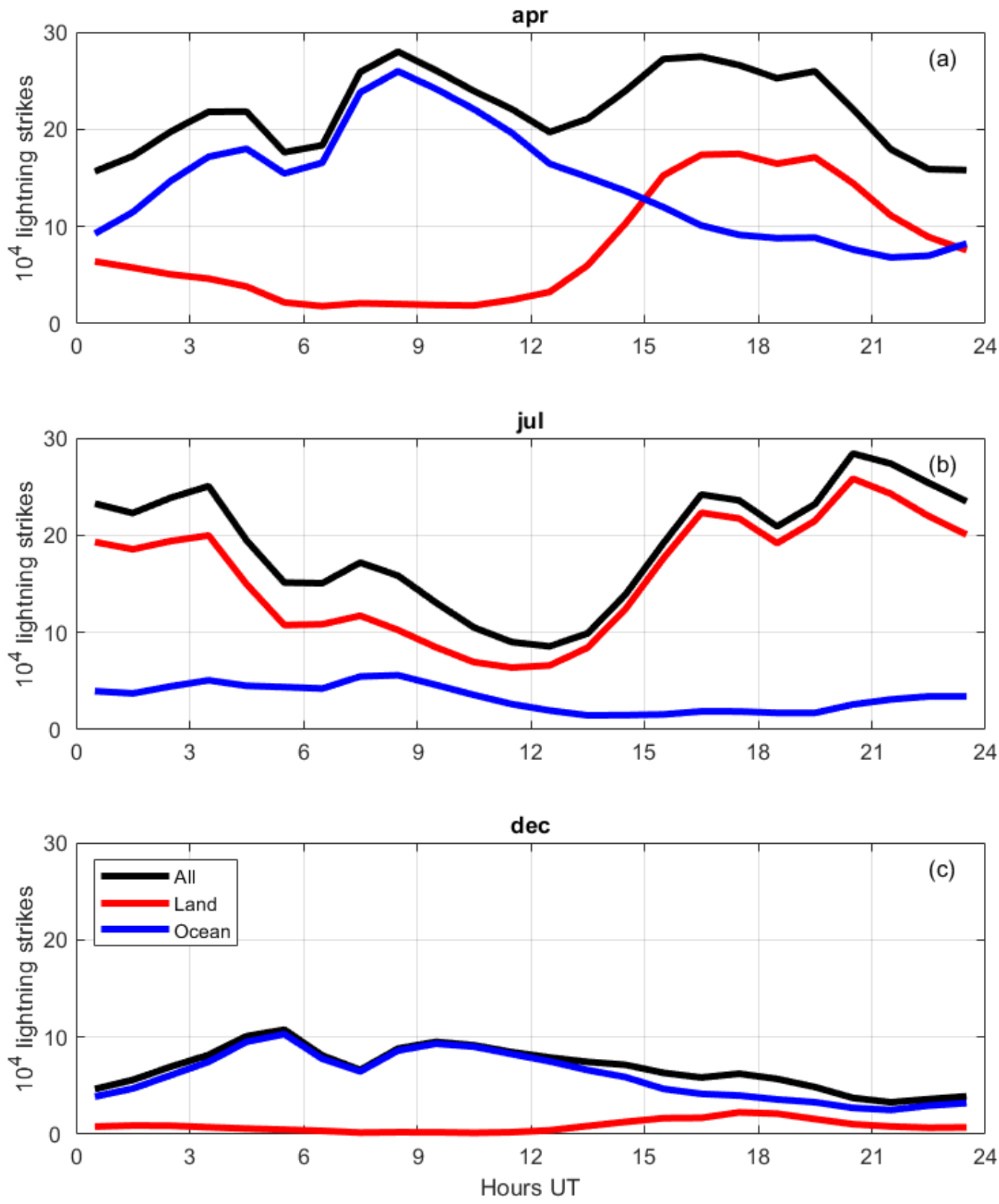

Figure 9: Number of total (black), land based (red) and ocean based (blue) lightning strikes within the $-20^{\circ}$ to $10^{\circ}$ longitude and $-10^{\circ}$ to $20^{\circ}$ latitude box centred over IS 17 , binned by hour of the day for the month of (a) April, (b) July and (c) December. 
(a)

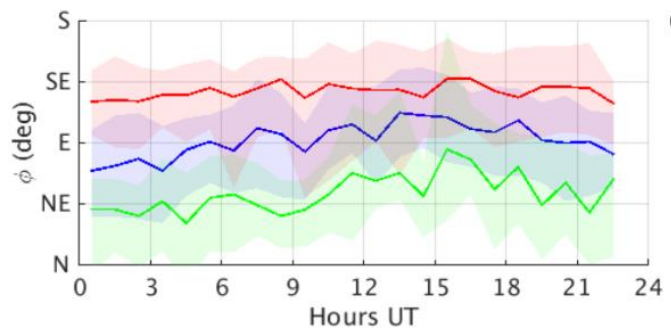

(c)

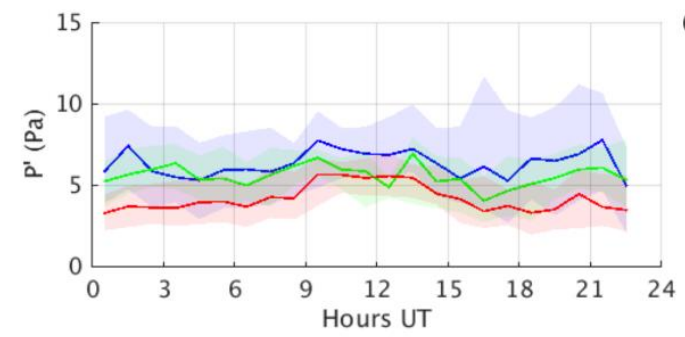

(e)

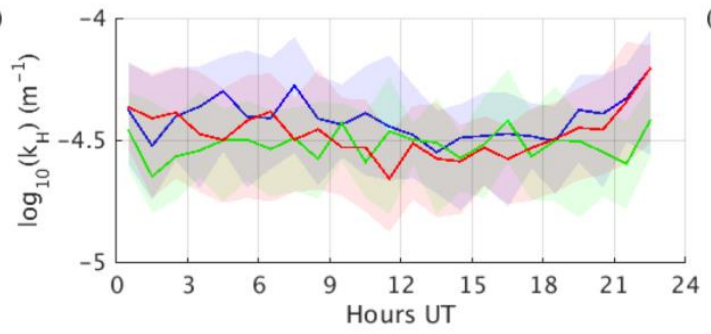

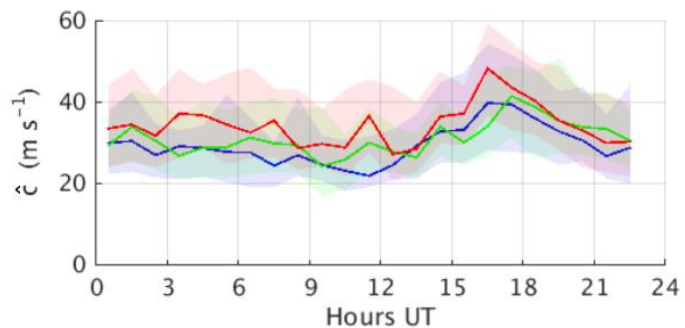
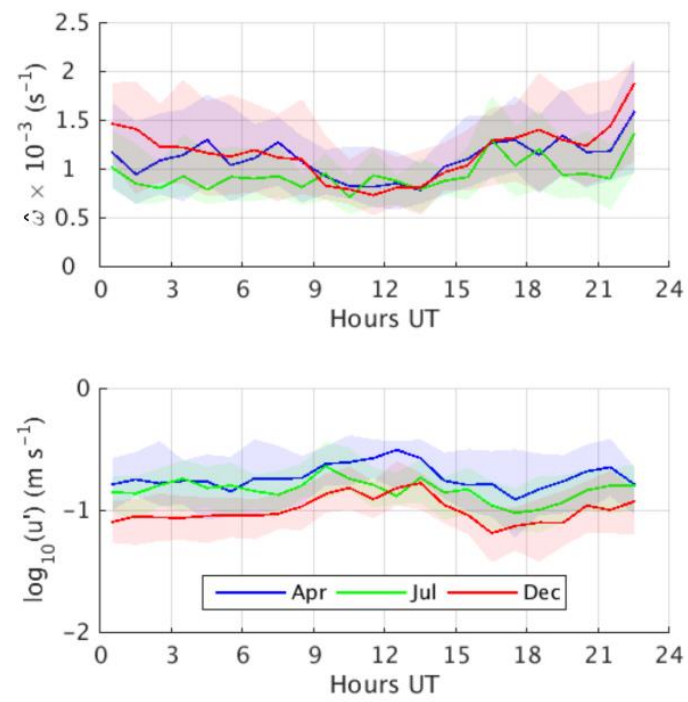

Figure 10 Time series showing the median (solid line) and interquartile range (shaded) for a) back azimuth $\phi(\mathrm{deg}), \mathrm{b})$ intrinsic wave speed $\hat{c}\left(\mathrm{~m} \mathrm{~s}^{-1}\right)$, c) pressure perturbation $\left.\mathrm{P}^{\prime}(\mathrm{Pa}), \mathrm{d}\right)$ intrinsic frequency $\widehat{\omega}\left(\mathrm{s}^{-1}\right)$, e) $\log _{10}$ horizontal wave number $\left.k_{\mathrm{H}}\left(\mathrm{m}^{-1}\right), \mathrm{f}\right) \log _{10}$ horizontal velocity perturbation $\mathrm{u}^{\prime}\left(\mathrm{m} \mathrm{s}^{-1}\right)$ all binned by hour of day for days in April (blue), July (green) and December (red) between 2007 and 2011. 


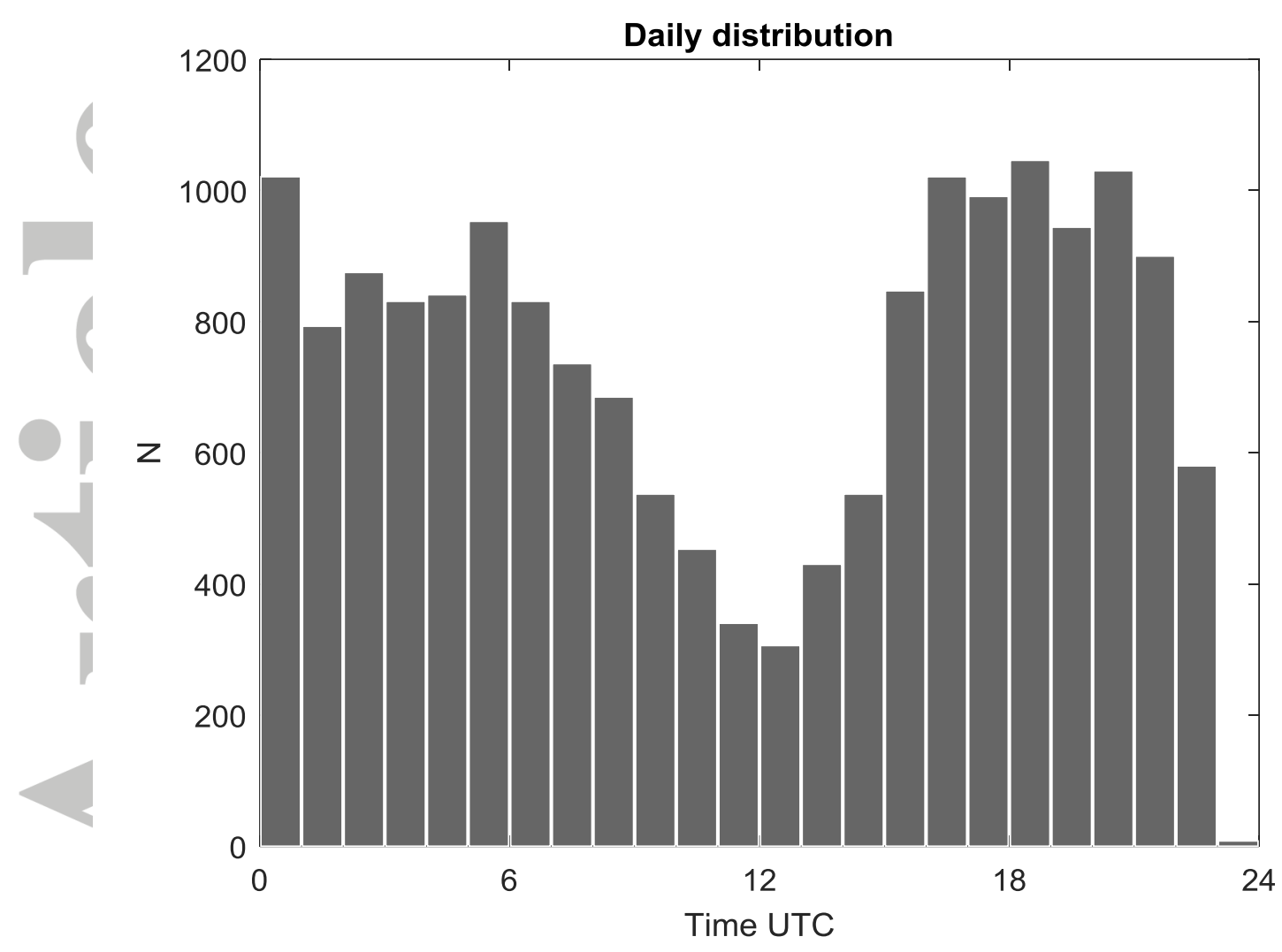

Figure 11: Distribution of the number of gravity wave arrivals at the Ivory Coast station (IS17) by hour of day for the period 2007 to 2011.

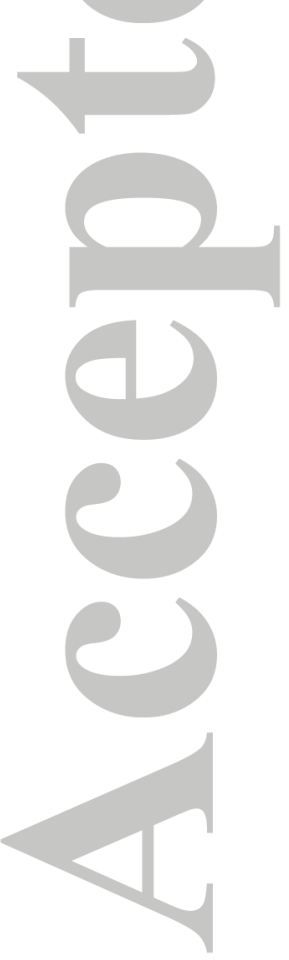

